\title{
Values Transmitted in Professional Education: Cases of Social and Health Care Sector and Police Administration Education in Finland
}

\author{
Päivi Huotari, Olavi Kujanpää, Maarit Sihvonen, Jari Stenvall \\ University of Tampere, Finland
}

\begin{abstract}
The aim of this paper is to study what kind of organisational culture values are transmitted in education with its objectives in working life readiness. In other words, does education that provides professional expertise empower the cultural values needed in working life. The empirical material is gathered among students with working life experience and studying in sectors differing from one another: social and health care and police administration. The theoretical basis of the study is Hofstede's (1992)[1] Onion Model, according to which the core of an organisational culture is made up of values that are often unconscious conceptions of good and evil. Hofstede presents four cultural dimensions: Power Distance, collectivism vs. individualism, femininity vs. masculinity, and Uncertainty Avoidance. Education provides students with a foundation of values that they will bring along into working life. The results of the study will answer the questions what kind of value basis education will provide for students and what is this explained by. On the basis of the new information, professional education institutions can reform their teaching and examine how education is corresponding to the needs of working life.
\end{abstract}

\section{Introduction}

Analyses and development of education are often concentrated on the perspective of professional readiness. Operations in working life are, however, also significantly affected by different manners, habits, values, and applied meanings. These can be called the organisational culture.

We are concentrating here to study two different professions, police and professionals of social and health care, from the point of organisational culture. These professions are interesting from the point of comparison due to the fact that both can be characterised as so-called semi-professions. Both of the studied professions also bear a strong ethical value basis.

Our study focuses on adult students. For instance, Finnish universities of applied sciences are arranging complementary, grade-oriented education for those working in the police force and in the social and health care sector. So, the empirical object group consists of students that are also involved in practical work.
In our study of organisational culture we are especially concentrating on values, in particular on masculine and feminine values. In other words, we are evaluating how masculine and feminine values differ from the adult students' perspective in police administration and in social and health care administration. We are also analysing the question from the point of education arrangements.

\section{Values, education, and working life}

The relationship between education and values has especially been discussed in research concerning professions. Among other things, it is typical to professions that the members share long education and strong professional codes based on values [2] [3]. Education plays, on the whole, a significant role in building up professional identities [4] [5].

The idea that education should contain more than just the transfer of knowledge also has long traditions. Values education is a part of the tradition of philosophy that started with the Greek concept paedeia (source of the word "pedagogy").

In fact, values education must be seen as a part of a wider human development process. It is what makes a person whole; culturally, politically, and mentally. From this perspective, the value skills produced by education are a part of reflective behaviour [6]. Ideally, they can be used for strengthening professional and responsible attitudes. Students can learn a wider approach to theoretical and practical work analysis and not just by finding solutions that appear technically correct. Students are able to develop their intellectual, dialogical, and moral expertise by evaluating what would be the right solution viewed from different angles.

The correspondence of vocational education and working life has been examined in various studies. For instance, Puliyel, Puliyel and Puliyel [7] have studied the adult learning theory in personnel training and professional values. Coulehan and Williams [8], on the other hand, have studied the values in the education of medical doctors. Zedeck, Middlestadt and Hayes [9] have compared the values of police work between students and those in working life.

However, the question how the cultural values that affect the operation of organisations are appearing from adult students' perspective has not received much attention at all. The group of adult students is also 
interesting in the sense that because they have previous working experience and some professional education, they most likely already possess a strong value basis.

Another problem is that different studies are restricted to analysing values from the perspectives of good professional operation and professional codes. In our view, the values produced by education should also be analysed with respect to how they help in coping with the constant changes and reforms of working life. Professional groups and their values are often considered to be obstacles to operational reforms. For instance, ethics and observing the requirements of good professional work increase the autonomy of professional groups in development work [10]. For this reason, it is appropriate to consider the feminine/masculine aspect, because it affects the way in which people in working life take each other into account.

\section{Feminine and masculine values}

It is possible to examine organisational cultures from a number of different angles. In this conjunction we are applying the approach presented by Geert Hofstede. There, the core of organisational culture is formed by values that are often unconscious conceptions of good and evil, right and wrong. The values are something that is difficult to observe, or they are difficult to discuss. In organisational cultures you can study practices that consist of symbols, heroes, and rituals.

Hofstede presents four cultural dimensions. They are: Power Distance, collectivism vs. individualism, femininity vs. masculinity, and Uncertainty Avoidance. he cultural dimensions defined by Hofstede appear as dimensions of values that prevail in the lives of organisations. In this conjunction we are concentrating on the dimension of masculinity vs. femininity.

According to Hofstede, the femininity vs. masculinity dimension contrasts the acceptability of selfassertion and modest behaviour, and this is related to the role models offered by the parents. This dimension also emerged on the basis of the question of "the goal of work" presented earlier. In the masculine extremity, the following issues are very strongly emphasised: income (possibility to earn well), recognition (earned), progress and challenges (personal satisfaction through work). Masculinity also involves hardness, efficiency, materialism, and indifference towards others. Japan is by far the most masculine culture in the study [11]. The feminine extremity, on the other hand, emphasised the following issues: manager (good relations with the nearest superior), cooperation, living environment, and security of employment. Alongside other Nordic countries Finland is among the most feminine cultures.

This dimension can be defined as follows: "masculinity is related to societies where the social roles of the sexes are clearly different (i.e. men are expected to be firm and hard, and focus on material success, while women are expected to be modest, gentle, and interested in the quality of life". "Femininity is related to societies where the social roles of the sexes are overlapping (i.e. both men and women are expected to be modest, soft, and interested in the quality of life)".

The police can be considered a traditionally masculine field of occupation while nursing would be feminine, which also justifies the comparison of these fields. Different studies are also suggesting that the values in these fields are strongly connected with the professions [12], [13]. On the other hand, some results in police administration are showing that the individual system of values is more important than professional socialisation in understanding the behaviour of the police. A model of values is not just consistent over time but it is also reflecting with conservative beliefs [14].

In practice, also the question of police administration representing unambiguously masculine and nursing feminine values is not self evident. For instance, masculine factors related to instruments have been observed in nursing [15]. Correspondingly, soft feminine values have been identified in police administration [16].

\section{Background}

There are major administrative changes in progress in Finland, and they are moulding the operations of the public sector also concerning the social and health care sector and police administration. As a rule, social and health care services are administered in Finland by municipalities and they enjoy strong self-governance. Police administration, on the other hand, is a part of state administration even at the local level.

The local administration level is currently being moulded by the PARAS [17] project and the police administration by the PORA [18] project. In addition, Finland is engaged in the Bologna Process [19]. The PARAS project involves the structures and services of municipalities. According to the PARAS legislation, the units offering the basic health care services as well as those of the closely related social services must cover areas with at least 20,000 inhabitants. Some of the Finnish municipalities arrange the basic health care services themselves; some have common health care centres or cooperation in the arrangement of on-duty services, while others arrange all their basic services within cooperation areas. Administration is typically scattered, with plenty of different variations.

Within the PORA project, police administration has been developed so that the 90 district police departments are reduced in number to 24 police department. Licensing services are increasingly provided as joint services. Cooperation and specialisation in demanding tasks is being developed between police departments.

Education also changes along with the administrative structures. Finnish higher education institutions are engaged in the Bologna Process with the aim to create a common European higher education area by the year 2010. The objective is to make European higher education institutions attractive, and this is aimed at by 
adopting comprehensible and streamlined examination structures, the introduction of common study unit systems, increased mobility, quality assessment, and international networking.

The Finnish education system has aimed at strengthening the role of polytechnics as producers of professional competences. This has meant longer education times and opened up possibilities to study for advanced degrees at polytechnics. The core idea is still, however, that polytechnics concentrate in particular on education to provide professional competences, whereas the role of universities is geared to scientific education.

\subsection{Data}

The material in this article consists of Finnish students in social and health care as well as police training institutions. The material is part of a larger research project comparing the values of students and those already working.

The material concerning social and health care students was gathered among adult students at the Lahti Polytechnic. It is one of the largest polytechnic institutions offering social and health care education in Finland. Police training is concentrated in Finland to one institution. The material for this article was, naturally, gathered in that institution, the Police College of Finland, located in Tampere.

In this conjunction the focus will be on students who were receiving further education. For instance, some of the social and health care students were upgrading their degrees to Bachelor level. These studies provide competences required of superiors, such as officers in police administration and immediate superiors in the social and health care sector.

The inquiry was implemented by electronic means (Webropol) in September 2009, and it was sent to 235 students in social and health care and 82 police students. 88 of the social and health care students replied and 42 of the police students. The response percentage was 41 . The material was rather small, especially regarding police students, because the number of students in the annual courses is small (about 15-20 students/year). The response percentages were, however, quite high although the percentages were undoubtedly affected by the electronic implementation of the inquiries. The material is, nevertheless, sufficient to provide an indicative overall view of the students' ideas of the values related to the operation.

Of the total number of respondents 68.5 percent were social and health care students and 31,5 percent police students. The respondents were adult students who were upgrading their earlier degree in the same field to a bachelor-level degree. Half of the students were in the age group 35-45 years and as much as onefifth in the age group 46-50 years. A typical adult student in Finland actually is a 35-45 years old married woman with children, and she is supplementing her education while working full time.

\section{Results}

\subsection{The importance of values in education}

Frequency distributions were taken of the material and sum variables were formed. The formed sum variables were: (1) equality in management-employee interaction, (2) authoritarian management, (3) equality between members of working community, (4) management of groups, (5) management of individuals, (6) predictability of work, and (7) unpredictability of work.

When the fully or partly agreeing responses in the frequency variables were combined, the result was that all police students who had replied had the opinion that their profession is valued in the society and that they themselves value their own profession. Three out of four of the social and health care students also experience that the society values their profession. However, they value their own profession higher themselves.

Police students are more committed than the students in the social and health care sector to stay in their profession until retirement. All police students also had clear objectives regarding their own careers. The same applied to nearly $90 \%$ of the students in social and health care.

The inquiry included an open question asking the respondents to give their views on how value education is manifested in teaching. The responses of social and health care students contained more statements of the sufficiency of value education than of its insufficiency. However, a small proportion of the respondents had the opinion that value education should be strengthened. According to the respondents, value education is an inseparable part of learning the profession. Learning values was considered interesting, many-sided, and important from the point of future working life. To learn the values of one's own profession it would be essential that teaching would be more closely connected to the working practice and the operating models of the working community within the profession. According to some students, the managers in the social and welfare sector are not sufficiently familiar with the importance of values for management.

In the responses of police students, on the other hand, the lack of discussion on values in education as well as the working community emerged as a central issue. Open discussion on values, and education to make values a part of the daily operations were on the wish list in most responses. The responses reflected that values remained the knowledge of a too small group, and common, wider knowledge and practical implementation in everyday work was missed.

The material is, in fact, suggesting that a deeper consideration of the working community's value basis in education could partly also contribute to development in working life. On the other hand, going through the values and rules of working life enables humanoriented management, where employees are seen as a 
resource of the organisation. Values can be linked into working community training as a natural part of education. Students also wished to have more discussion and awareness of values related to life, not just emphasis on the values according to the arguments of results and productivity. On the other hand, students had doubts whether it would be possible to learn values through education.

\subsection{Femininity vs. masculinity in working life}

About four students in five in all sectors considered it important that their work is challenging. Students did not consider personal achievements as the most important feature of their work. Instead, three out of four considered that the worker's competence must be a basis for his/her pay and advancement in career.

The observance of rules and regulations was considered very important especially among police students. Replies to the open question also contained comments supporting this view:

"Police work is to a great extent based on law, and the constitution of Finland is among the most important of them. The values are found in our constitution, which contains values corresponding to the Human Rights Agreement, for example. Law must be obeyed and laws of lower level than the constitution must be in harmony with the constitution..."

The students' views differed regarding how they saw the supervisor's monitoring and control responsibilities with respect to their own work. It is even possible to see that rules and supervision are playing a very important role in keeping the operations aligned with the instructions - this interpretation would render individual action rather undesirable.

"The education emphasised internal training in the units, where the visibility of values and the development of operating practices can be taken up. According to the information given in training, the development of a working community benefits from the utilisation of youth and keenness, but also from having the experienced old soldiers along."

"Values are the mental backbone of a working community, and they guide the individual choices of workers, i.e. the operating practices. Values should be jointly agreed, but in practice the values of police, for example, are defined in "inner circles". But this is, in fact, the only feasible way...."

About $60 \%$ of the police students accepted this, while the corresponding proportion of the other students was only one-third. In this respect, police students more clearly represent the so-called masculine values.

The masculine values of police students is also reflected in that almost all considered it important that subordinates are told what they are expected to do.
Only about $60 \%$ of the social and health care students had the same opinion.

Students are not working to be able to earn a living. Only one third have earnings in mind. Both police and social and health care students are studying for a vocation. None of the police students thought that material success is the most important thing, and even among the social and health care students only $10 \%$ had that opinion.

Instead, nearly all police students valued good human relations in the working community. In other words, the values among both police and social and health care students were also strongly feminine.

Four in five thought that they will be able to do their work independently. Less than $10 \%$ of the students held the idea that competition between workmates would be emphasised. In other words, students seem to have faith in the possibility to combine independence and collectivity.

Students believe that they will be faced with a quite strongly masculine culture regarding success at work. There were, however, differences between the professions in how the members of the working community would help those with poorer performances. $60 \%$ of the social and health care students but only one third of police students expected they would be helped.

\subsection{Femininity and masculinity, and values pro- duced by education}

When the dimension of femininity vs. masculinity is examined with regard to what kind of values education is transmitting, there are differences between training in social and health care and police. The social and health care students are emphasising more than police students the equal interaction between the management and the workers and between members of the working community, whereas authoritarian leadership was more emphasised in the training of police students.

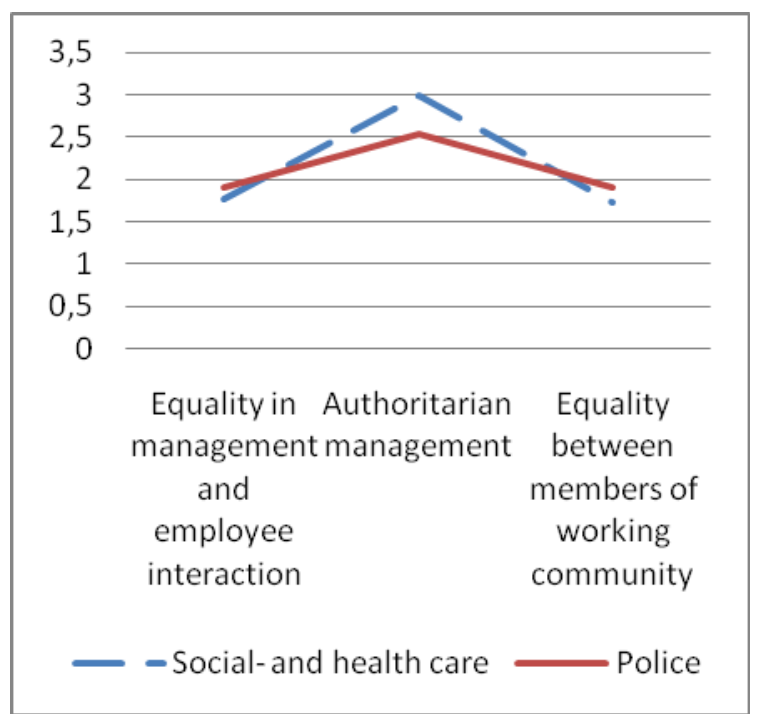

Figure 1. Equality in management 
The equality of interaction between management and their subordinates was shown in the training of those social and health care students who were upgrading their education, with some of them already working as superiors. Giving feedback to superiors and the openness of interaction were strongly transmitted values in the training of all sectors.

Authoritarian leadership with an emphasis on masculine values appeared strongest in police training and weakest in further education for the social and health care sector, although it was not a dominant way of handling leadership within any of the fields of education. More than half of the respondents did not consider that training was emphasising the leader's authority and independent leadership, but, on the other hand, one-third of the respondents thought that this type of leadership was emphasised. Nearly $40 \%$ of the respondents considered that their training is transferring views of the superiors' task to monitor and control work assignments, while only one-third did not see that their training would be transferring such leadership practices through teaching. Training did not, however, underline formal communication, and only $18 \%$ of the respondents saw their training to be transferring a model of formal communication to the students. Training is, however, more strongly transferring the meaning of hierarchy in the distribution of information inside and outside the organisation.

Emphasising femininity, equality between the members of a working community was according to the results transmitted in all sectors of training, but the trend was the strongest in upgrading studies within social and health care. A comparison of the average results gave police training a slightly lower value than the others. Nearly $65 \%$ of the respondents experienced that their training is transmitting the value of equality between working community members, but $18.5 \%$ disagreed with the argument. As many as $90 \%$ saw that their training was transmitting the importance of discussion between superiors and subordinates in conjunction to the planning of operations and, according to the respondents (92\%), the training also emphasised that the responsibility for successful operation lies with every member of the working community. In the same way, training is strongly transmitting (92\%) that new workers and outsiders should be openly received by the working community. According to the respondents (nearly $80 \%$ ), open communication of information in the working community was also emphasised in training. The relationship between employer and employee is in training based on mutual benefits (83\%).

Leadership of a community and a group related to feminine values was transmitted strongest in the social sector education and weakest in police training. According to the respondents (75 \%) education emphasises group leadership in teaching, and that collectivity as well as the unity of expertise and knowledge are important values. Training also emphasises the importance of good human relations in the working commu- nity and that being a member of a working community has a motivating effect on good working performances (about $90 \%$ of the respondents).

Collectivity may not, however, be placed above the task and, according to the respondents, training does emphasise the priority of the basic task over human relations within the working community. Training transmits equality and solidarity and helping those with poorer work performances, but in police training this trend is not as clear as in the social and health care sector. In solving disputes, compromises and negotiations were emphasised (about $80 \%$ of the respondents).

Only one in four students experienced that their training was emphasising personal achievements and with material success the figure was only one in ten. The challenging nature of work was strongly emphasised in training (86 \%). $38 \%$ of the respondents considered that training expects the workers to exhibit firmness, ambition, and strength, but $42 \%$ disagreed with these views. According to $70 \%$ of the respondents, training emphasises strength, but does not, however, emphasise competition between workers and performance.

\section{Discussion}

The students in the studied fields of education showed strong commitment to their own occupation and profession. In this sense, the results can be partly considered to be reflecting the interpretations students have concerning the professional identities of their respective professional fields.

On the basis of the material it seems possible that for those in working life, grade-oriented professional education is linked with masculine values. The students' values had a clear emphasis on the importance of competence within the field and on a pay according to it. On the other hand, it must be remembered that the target group in our study were people in working life that had sought education. It is likely that this group is participating in education in order to improve their competences and with it also their pay. At the same time, however, their professional identities also contain femininity in that the work is not done just for earning money but also as a vocation.

Police students represent, as expected, more masculine values than social and health care students. They accept the hierarchy involved in their work, as well as the related monitoring and instructions. According to the students' views, both professions have quite strong feminine values. Nevertheless, especially concerning the feeling of compassion the values in social and health care are softer than in the police. This is understandable as empathy is considered a part of the work with customers within social and health care.

The contents of the offered training also reflects the values described above and the differences related to them. It is possible to say that education is reflecting and reproducing the values existing in working life. In 
this respect, our study confirms the view presented in profession research that the values of education and professional operation are closely connected with each other (e.g. Abbott 1988). To some extent, his seems to be self-evident, without any critical discussion on values in conjunction to education.

An important aspect arising from the material is the fact that masculine and feminine values are not unambiguously opposite elements in working life. The material even suggests that acting according to masculine values is a condition for feminine values. If working life contains performance at work and action according to competences, then collective and interactive values will also be present. In other words, the working community is harmonious when the workers are able to manage their professional challenges

Even regarding studies, values appear contradictory. For instance, the material shows quite strong emphasis of masculine values, which is manifested in the emphasis on, for instance, the challenges of the work, and on individual firmness and strength. If masculinity would be realised in a logical way according to the views presented by Hofstede, the students should be competing openly with one another and they would have competitive and even hostile attitudes towards one another. Despite the masculine features, however, both police and social and health care students experience that their education places little emphasis on competitiveness.

The material conveys a conception of the hardness of working communities. This is indicated in the expectations that the working communities would not necessarily show compassion towards those who have problems in performing their duties. The result can be understood against the background of, for instance, the challenges arising through constant change and the pressures at work. If somebody cannot perform his/her tasks, it will easily increase the burden of others. The police are also a profession that can be facing situations in which a decrease in a fellow worker's performance may cause danger to others.

It is, however, possible to ask whether professional education is generating lines of thinking and attitudes that are decreasing the feeling of compassion towards weaker performances. Actually, professional education is producing hard values, when it emphasises professional expertise and competence.

This will also separate the trained professionals from other actors. The outcome may, however, be that the workers with poorer performances are subjected to discrimination in their working communities and end up in the periphery.

All in all, our study has verified the need that especially regarding adult education and leadership competences, attention should also be paid on values related to working life cultures and not just on values with their background in professional codes. Secondly, in a certain cultural environment the values can differ from one another when related to studying, individual working, acting in a community, and in a supe- rior/subordinate relationship. For instance, even if a working environment would according to femininity be emphasising good human relations, management may be based on the emphasis of masculine hierarchy. It could be summarised that values related to education and working life should be treated with cultural and contextual reservations. Values are not logical in the practices of education and working life.

\section{References}

[1] Hofstede G. (1992) Kulttuurit ja organisaatiot. Mielen ohjelmointi. Juva: Geert Hofstede ja WSOY.

[2] Bockel, J \& Noordegraaf, M. (2006). Identifying identities: performance-driven, but professional public managers. International journal of Puclic Sector Management. VO 19, NO 6, pp. 585-597.

[3] Freidson, E (2001). Professionalism. Blackwell. Oxford.

[4] Berg, A-M (2006). Transforming public services transforming the public servant. International journal of Public sector management. Vol 19, NO 6. pp.556-568.

[5] Hatch, M. \& Schultz, M (Eds), (2004). Organizational Identity. Oxford University Press. Oxford

[6] Muijen, H. 2004. Integrating value education and sustainabledevelopment into a Dutch university curriculum. International Journal of Sustainability in Higher Education, 5 (1), $21-32$.

[7] Pyliyel, M.M.; Puliyel, J.M. \& Puliyel, U. (1999) Brawing on adult learning theory to teach personal and professional values. Medical Teacher. 21(5). 513-515.

[8] Coulehan, J. \& Williams, P.C. (2001) Vanquishing Virtue: The Impact of Medical Education. Academic Medicine; v76 No 6. pp. 598-605. ISSN 1040-2446.

[9] Zedeck, S. \& Middlestadt, S. \& Hayes, E. (1981) Police work values: A comparison of police science students and current officers. Journal of Occupational Psychology 1981, 54. pp. 187-194.

[10] Taylor. I \& Kelly, J (2006) Professionals, discretion and public sector reform in the UK: re-visiting Lipsky. Internatilnal Journal of Public Sector Management. Vol 19, n:o 7, s. 629-642.

[11] Aaltonen T., Junkkari L. (1999) Yrityksen arvot \& Etiikka. WSOY, Porvoo.

[12] Khokher, Patricia, Bourgeault, Ivy Lynn \& Sainsaulieu, Ivan (2009) Work culture within the hospital context in Canada: professional versus unit influences. www.emeraldinsight.com/1477-7266.htm.

[13] Zydziunaite, Vilma \& Katiliute, Egle (2007) Improving motivation among health care workers in private health care organizations. A perspective of nursing personnel. www.emeraldinsight.com/1746-5265.htm. 
[14] Caldero, Michael A. \& Larose, Anthony (2001) Value consistency within the police: the lack of a gap. http://www.emerald-library.com/ft.1.10.2009.

[15] Kasila, Kirsti, Poskiparta, Marita \& Villbeg, Jari (2006) Cultural and communicational traits of oral health care: results of Finnish case study. www.emeraldinsight.com/1477-7266.htm.

[16] Zao, Jihong, He, Ni \& Lovrich, Nicholas P. (1999) Value change among police officers at a time of organizational reform: a follow-up study using Rokeach values. Plicing: An International Journal of Police Strategies \& Management, Vol. 22 No, 2. pp. 152-170.

[17] Stenvall Jari, Vakkala Hanna, Syväjärvi Antti, Leinonen Jaana, Juntunen Pekka, Oulasvirta Lasse \& Tiilikainen Aaro (2009) Parasta nyt - Kunta- ja palvelurakenneuudistuksen suunnitteluvaiheen loppuraportti. Valtiovarainministeriön julkaisuja 11/2009.

[18] Pora I -hanke: Poliisin paikallishallinnon kehittäminen. Sisäasiainministeriö.

http://www.intermin.fi/intermin/home.nsf/Pages/91DCDF8F 58463E34C225746500403C56. 22.5.2009.

[19] Bolognan prosessi (2009) http://www.minedu.fi/OPM/Koulutus/artikkelit/bologna/inde x.html. Opetusministeriö. 26.9.2009. 